Health \& Medicine | Mogens Hørder \& Marie Konge Nielsen

\section{Patients as partners in research - The challenges for researchers of patient involvement}

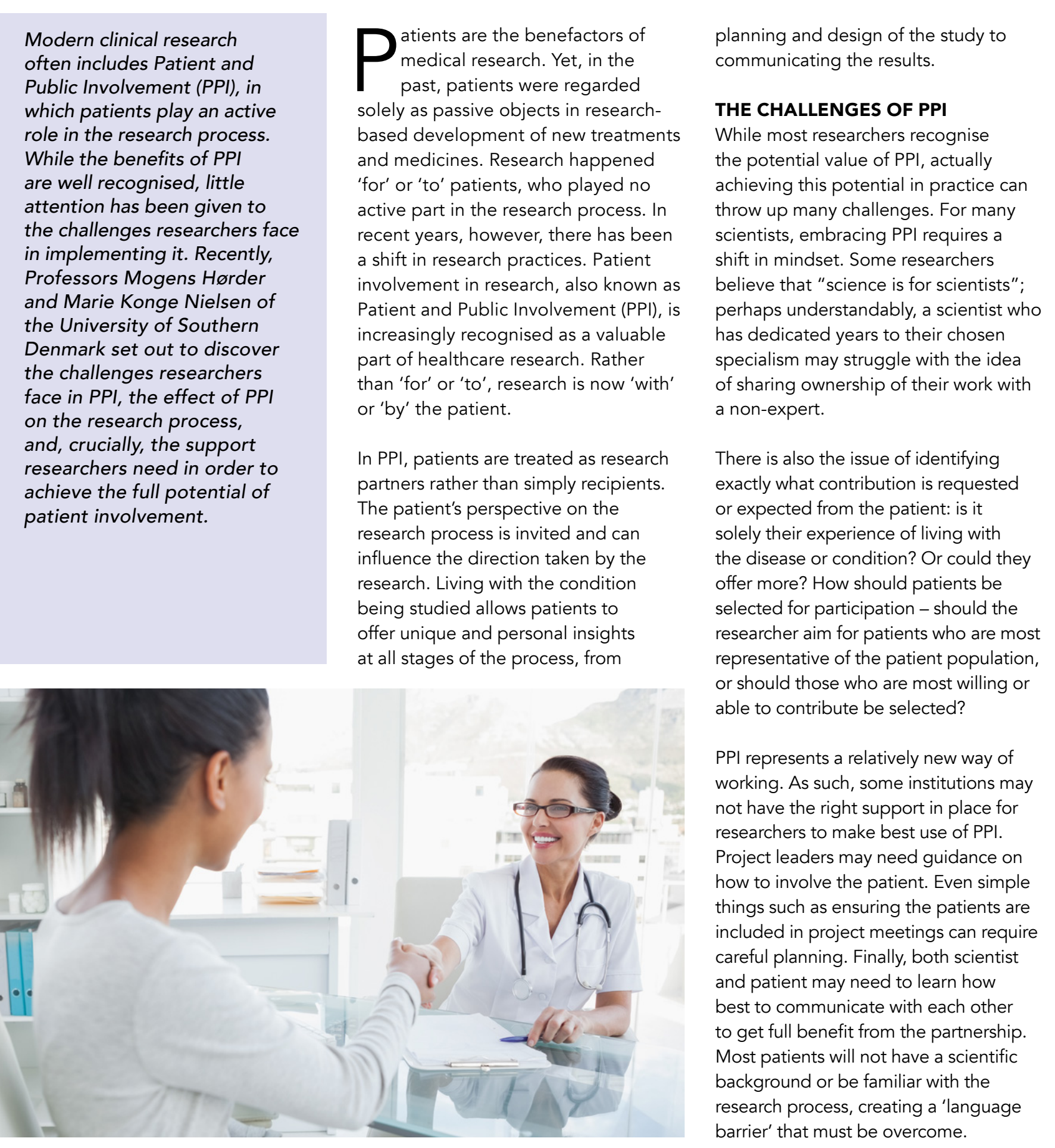

To better understand some of the challenges of PPI from a researcher's to potential problems, Prof Mogens Horder and Prof Marie Konge Nielsen of the University of Southern Denmark scoured recent literature on the subject. Their aim was to answer three questions: what challenges and barriers do researchers face in PPI? What are some of the effects of PPI on wellestablished research practices? And what support do researchers need?

\section{HOW DOES PPI AFFECT THE} TRADITIONAL RESEARCH PROCESS?

Most scientific, medical and clinical research follows a well-established path. The tradtional research process a hypothesis, designing a study a hypotiosis, designing a study, robust and reliable. While incosuls - is PPI does not mean that this process will be overturned, it does mean that it might be approached in new ways.

In PPI, the patient's perspective informs the research goals. When researchers are open to this, the view of the patient can steer the direction of the research, reveal overlooked issues, influence study design - and, crucially, ensure that the outcome is patient-centred. This has been particularly successful in arthritis research, in which patients have driven a new focus on quality-of-life measures such as chronic fatigue and sleep problems.

Prof Hørder and Prof Nielsen found that, according to many researchers,

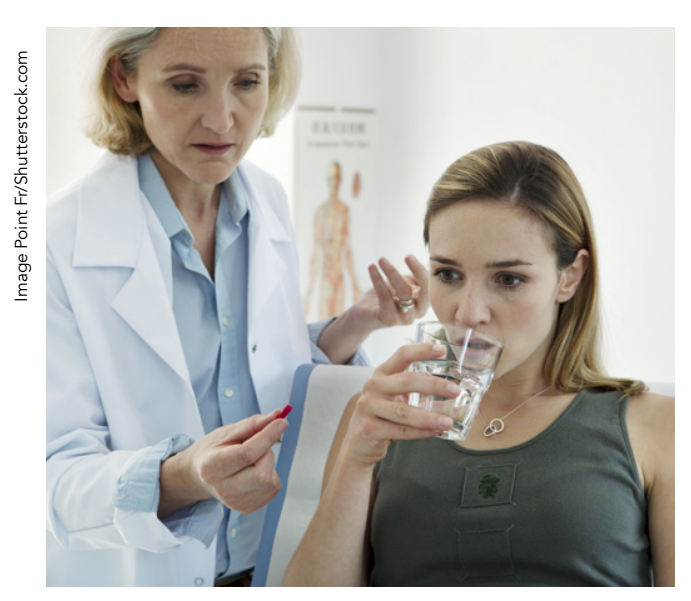

Patients have always played
been less relevant (right)

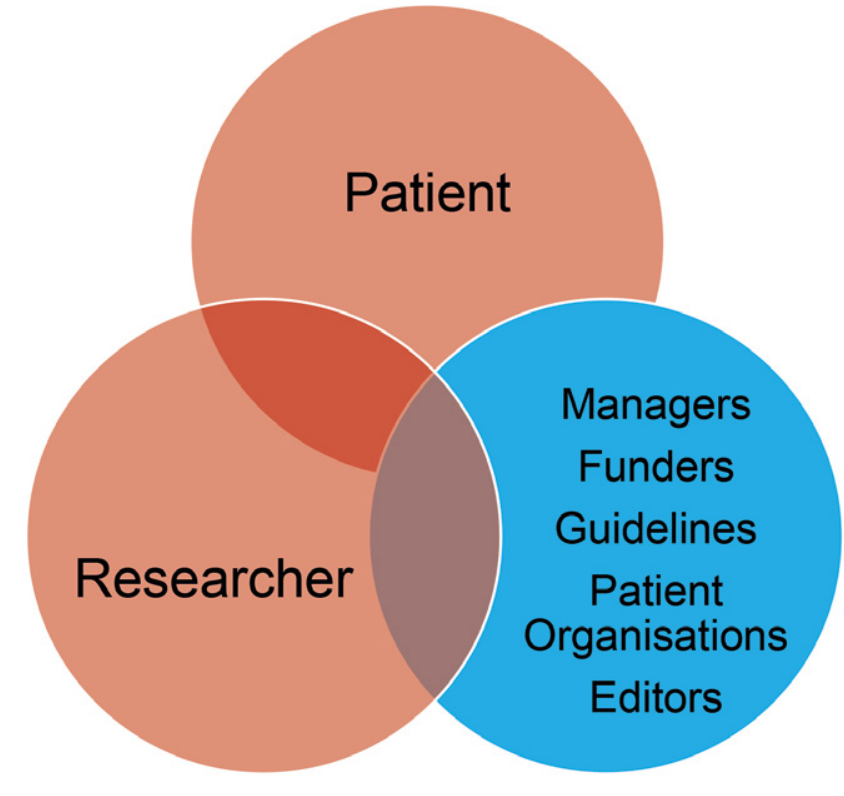

The PPI partners - the patient and

by third parties (blue)

INSTITUT FoR
SUNDHEDSTJENESTEFORSKNING SDUঞ́

While most researchers recognise the potential value of PPI, actually achieving this potential in practice can throw up many challenges.

the potential of PPI varies according to While the success of PPI may vary from the type of study. While PPI might be project to project, most researchers smoothly included in clinical research expressed a view that they are themselves changed by the process patient involvement, even if only as basic research (which seeks to expand discuss their work in more accessible knowledge, rather tha lead directly to language, avoiding scientific jargon. a new treatment, for example).

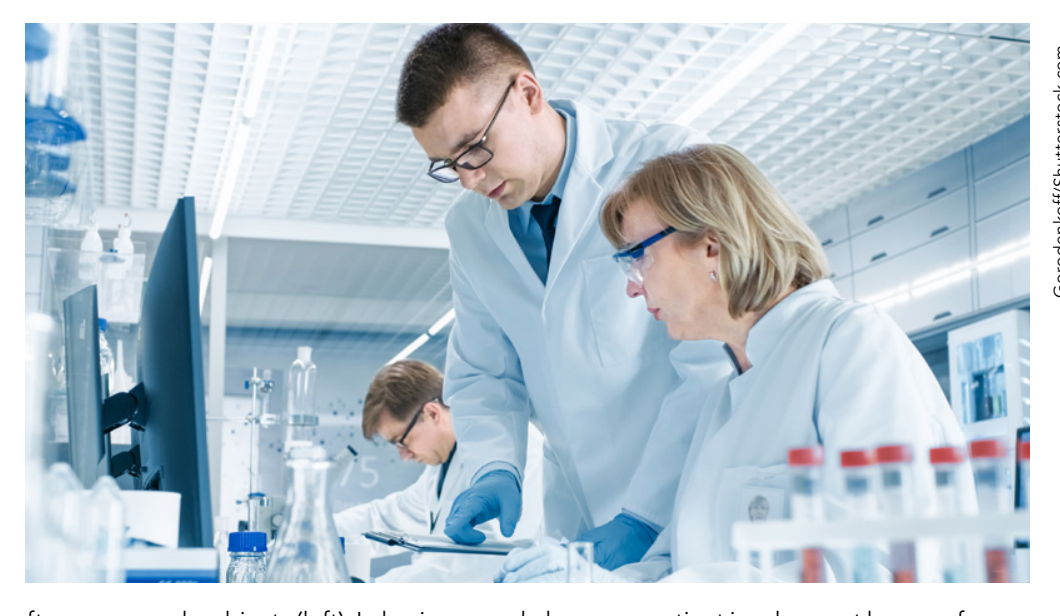




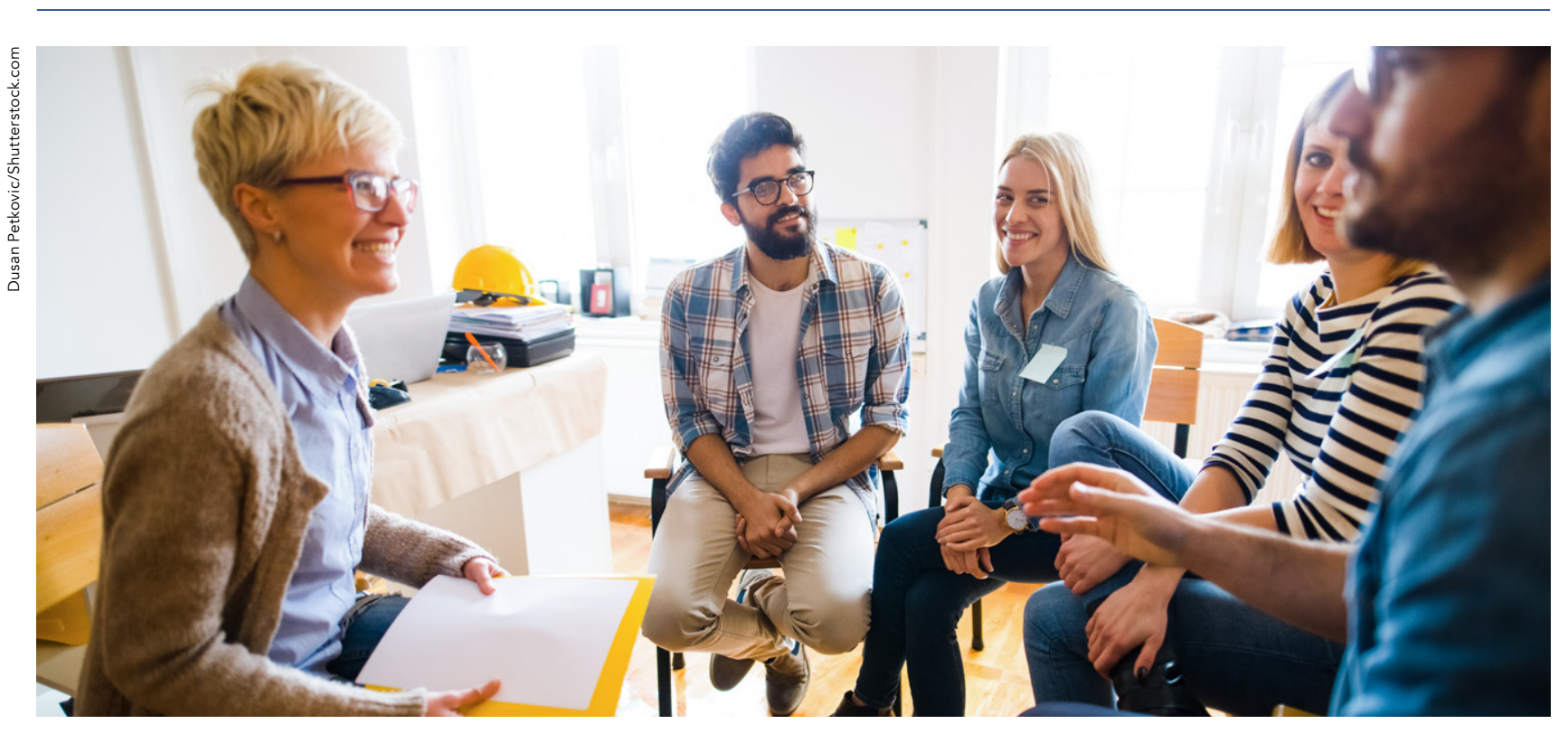

For successful PPI, both researcher and patient may need training. For the patient this may include familiarising themselves with the fundamental
ideas of the research process.

ability to share their work with a wider audience.

Prof Hørder and Prof Nielsen believe that researchers return to one question: "How will involving patients affect my project?" There is no single answer to this question. PPI will impact the research process of each project in a slightly different way. Nevertheless, PPI will likely reveal new issues or problems to consider - and perhaps solutions to investigate by research, as well.

WHAT SUPPORT DO

RESEARCHERS NEED?

It is clear that there is no 'one-size-fits-
While the researcher leads the project - and takes overall responsibility is importicipant that the roles of each This should be done as early in the project as possible, so that realistic expectations can be set. With the support of their institution, researchers could even consider written 'job descriptions' for both themselves and patient participants in order to clarify roles. Another possibility is for researchers experienced in PPI to to the task.

Both researchers and patients may need training in PPI. For the patient guide and mentor those who are new

Finally, researchers agree that institutions should offer practical extra financial support - in meeting patients' transport costs, for example - and help with budgeting. Institution could also take responsibility for ensuring diversity in PPI: in the ethnic, cultural and educational backgrounds of participants.

THE FUTURE:

PATIENTS AS PARTNERS

If PPl is to have value, the commitment of the researcher is key. There are many challenges for the researcher Prof Harder and Prof Nielsen PPI. Prof Hørder and Prof Nielsen believe project. However, there are a few that are importan that are important
in successful PPI - ind institutions should ideally have PPI will likely reveal new issues or these challenges problems to consider - and perhaps little attention solutions to investigate by research. $\quad \begin{aligned} & \text { To overcome } \\ & \text { problems and }\end{aligned}$ the proper support in place to allow. researchers to address these points. an early stage in the research process. This allows patients to understand and influence the aims of the project at the planning stage. It also enables then to have a sense of ownership over the work. Second, researchers should ensure that patients understand how and why their contibution is valuable. If addressed propelly, these factors will strengthen the collabo
patient and researcher. this could cover the fundamental ideas of the research process: that research builds up knowledge that is based on data, that methodology is based on certain principles and theoretica assumptions, for example. For the researcher, training in communication - which could cover everything from discussing methods and results to chairing meetings - is likely to be beneficial. Researchers and patien could even participate in training their relationship. motivation of both researcher and patient participant, the support of the institution is crucial.

With the right support in place, researcher and patient will be able to work together in a constructive and mutually beneficial way. At its best, this collaboration will contribute to new scientific discoveries. A positiv experience of PFill lead the researcher to develop new skills and a richer level of expenience, thereby

\section{Behind the Research}

Dr Mogens

Hørder

E: mhorder@health.sdu.dk +45 60113015 W: https/pr sdu.dk/da/persons/MHorder

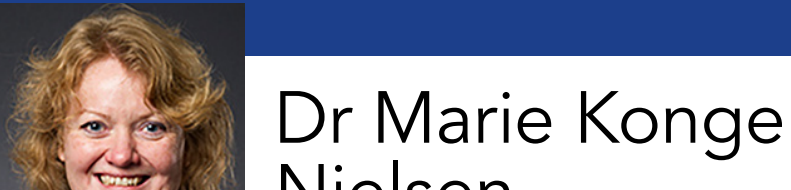

\section{Nielsen}

E: mkni@health.sdu.dk

T: $+4522569060 \quad$ W: https://portal.findresearcher. sdu.dk/da/persons/mkni

\section{Research Objectives}

Professor Mogens Hørder and Associate Professor Marie Konge Nielsen examine how patient involvement impacts research projects.

\section{Detail}

Mogens Horder

J.B. Winslowsvej 9.B.

5000 Odense C.

Denmark

Bio

Mogens Hørder is currently Professor at the Department of Public Health,

University of Southern Denmark, the

research interests are the developm implementation and evaluation of

Research (PPI) at project as well as instictional level He focuses on the in PPl and the interaction of the two as partners. Since 1964, Hørder has published more than 200 publications within clinical application of basic biochemical and molecular knowledge and on health services research - most recently on patient involvement in research (h-index 33).

Marie Konge Nielsen's research

she has been working with patient

empowerment and involvement in (elemedicine. She has a background Professor at the Department of Public Health, Research Unit on User Perspectives, University of Southern Denmark.

Danish Board of Health supported Mogens Hørder's project on the 2016-2019

Collaborators

Knowledge Center for Patient

\section{References}

Nielsen, M.K., Sandvei, M., and Hørder, M. (2018)

Forskerens perspektiver på patientinddragelse i forskning. Ugeskr Lægers, 180, V06180416.

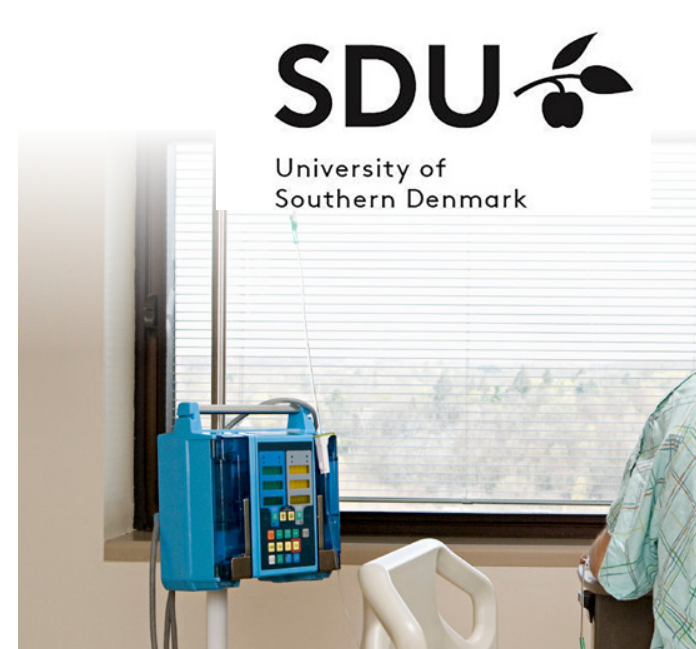

\section{SDU}

\section{Personal Response}

Inour opinion, what factor is mo helping researchers to tackle the challenges of PPI?

II Of major importance is to get started, to gain experience with PPI, to ensure feedback from patients and to share experiences among colleague researchers: "Wnil she has asked the patient." "Kristina Stas not. know

\section{.}

